Brazilian Journal
of Chemical
Engineering

ISSN 0104-6632

Printed in Brazil

www.abeq.org.br/bjche

Vol. 29, No. 01, pp. 61 - 67, January - March, 2012

\title{
PRODUCTION OF BIOEMULSIFIERS BY Yarrowia lipolytica IN SEA WATER USING DIESEL OIL AS THE CARBON SOURCE
}

\author{
F. A. S. D. Souza ${ }^{1 *}$, A. A. Salgueiro ${ }^{2}$ and C. D. C. Albuquerque ${ }^{3}$ \\ ${ }^{1}$ Universidade Federal Rural de Pernambuco, Laboratório de Tecnologia de Bioativos, Recife - PE, Brasil. \\ ${ }^{2,3}$ Universidade Católica de Pernambuco, Núcleo de Pesquisas em Ciências Ambientais, \\ Rua do Príncipe 526, Boa Vista, CEP: 50050-900, Recife - PE, Brasil. \\ Phones: + (55) (81) 9761-1755, Fax: + (55) (81) 2119-4043, \\ E-mail: fabiana.americasouza@yahoo.com.br
}

(Submitted: April 14, 2011 ; Revised: September 21, 2011 ; Accepted: October 24, 2011)

\begin{abstract}
The objective of this work was to investigate, on a flask scale, the production of bioemulsifiers by Yarrowia lipolytica in the presence of sea water, supplemented with nitrogen and phosphate sources, using diesel oil as substrate. A full $2^{4}$ factorial design was conducted to investigate the effects and interactions of the nutrient concentrations (diesel oil, urea, ammonium sulfate and monobasic potassium phosphate) on the response variables: emulsification activity and surface tension of the cell-free cultures. High emulsification activities ( $>5,4$ UEA) were determined after $168 \mathrm{~h}$ in all the experiments. The interactions among diesel oil, urea and monobasic potassium phosphate favored the emulsification with statistical significance. A correlation between the increase of emulsification activity and the reduction of surface tension was not identified.

Keywords: Biosurfactant; Bioemulsifier; Diesel oil; Sea water; Yarrowia lipolytica; Factorial design.
\end{abstract}

\section{INTRODUCTION}

Accidents during the transport of oil and its derivatives have caused serious damage to the environment. Pollution in marine water, especially oil spills, is a great danger to living organisms. All over the world, research and development of technologies for bioremediation and prevention of oil spills are stimulated.

Conventional techniques for cleaning areas contaminated with petroleum and its derivatives can be complemented in the remediation process by the presence of chemical dispersants or surfactants. Compared with synthetic surfactants, biosurfactants have greatest tolerance to variations of $\mathrm{pH}$, temperature and salinity. These compounds are more selective, less toxic and biodegradable. In addition, they can be produced in situ by microorganisms in the presence of organic contaminants as substrates (Desai and Banat, 1997).
The microbial degradation is influenced by the diesel oil hydrophobicity, which limits the mass transfer to microorganisms. This limitation may be overcome either by the addition of emulsifiers/ surfactants or by microorganism growth that produces emulsifiers/surfactant. These compounds are widely used to increase diesel oil bioavailability (Herman et al., 1997). When a major oil spill occurs, in either a marine environment or fresh water, the supply of carbon increases and the availability of nitrogen and phosphorus becomes the limiting factor for oil degradation (Atlas, 1984). On the other hand, excessive concentrations of nutrients can inhibit the biodegradation process (Challain et al., 2006).

According to Ochoa and Vazquez-Juaréz (2004), sea water used in the formulation of culture medium for the development of marine yeast provides minerals and nutrients, promotes growth selectively, and reduces costs and risks from contamination.

*To whom correspondence should be addressed 
The objective of this study was to investigate the production of biosurfactants/bioemulsificants by Yarrowia lipolytica in sea water, supplemented with sources of nitrogen and phosphorus, using diesel oil as the carbon source.

\section{MATERIALS AND METHODS}

\section{Microorganism}

A strain of $Y$. lipolytica was isolated from mangrove sediments in the city of Rio Formoso, in Pernambuco state and belongs to the culture bank of the Núcleo de Pesquisas em Ciências Ambientais (NPCIAMB) at the Universidade Católica de Pernambuco. This strain is named UCP 0988. The yeast was maintained at $5^{\circ} \mathrm{C}$ in Yeast Mold Agar (YMA) with the following composition: glucose $10 \mathrm{~g}$, tryptone $5 \mathrm{~g}$, yeast extract $3 \mathrm{~g}$, malt extract $3 \mathrm{~g}$, agar $15 \mathrm{~g}$, distilled water $1000 \mathrm{~mL}, \mathrm{pH} 5$.

\section{Diesel Oil}

Diesel oil used in the experiments was bought at a Petrobras gas station with the specifications: metropolitan B4 type (4\% biodiesel), maximum of $0.05 \%$ sulfur; with additives; contains paraffinic, naphthenic and aromatic hydrocarbons (10 to 40\%). This product is stable under the usual conditions of handling and storage.

\section{Physical-Chemical Characterization of the Sea Water}

The sea water was collected in the Port of Suape, Pernambuco. Its composition was $\mathrm{Ca}^{++} 1.00 \%$; $\mathrm{Mg}^{++} 0.97 \%$; $\mathrm{Na}^{+} 11.13 \%, \mathrm{~K}^{+} 0.88 \%, \mathrm{Cl}^{-} 20.50 \%$, $\mathrm{SO}_{4}^{--} 3.41 \%$; the salinity, specific gravity, $\mathrm{pH}$ and surface tension were equal to $37 \%$; $1026 \mathrm{~kg} / \mathrm{m}^{-3}$, 8.22 and $53.43 \mathrm{mN} / \mathrm{m}$, respectively.

\section{Experimental Design}

A full $2^{4}$ factorial design with four replicates at the central point, corresponding to a set of twenty experimental runs, was carried out to investigate the main effects and interactions of the independent variables: diesel oil, urea $\left[\left(\mathrm{NH}_{2}\right)_{2} \mathrm{CO}\right]$, ammonium sulfate $\left[\left(\mathrm{NH}_{4}\right)_{2} \mathrm{SO}_{4}\right]$ and monobasic potassium phosphate $\left(\mathrm{KH}_{2} \mathrm{PO}_{4}\right)$ concentrations, on the response variables emulsification activity and surface tension of the cell free cultures of $Y$. lipolytica in sea water after 168 hours (in order to allow for the production of a high amount of emulsifier). The independent variables and their minimum and maximum levels (Table 1) were chosen according Albuquerque et al. (2006). The inoculum was obtained from a pure culture of $Y$. lipolytica, maintained at a temperature of $28^{\circ} \mathrm{C}$ for $48 \mathrm{~h}$; the yeast cells were inoculated in sea water supplemented with urea $(0.4 \%)$, ammonium sulfate $(1.1 \%)$ and potassium monobasic phosphate $(6.12 \%)$. All the medium components were dissolved in sea water and the $\mathrm{pH}$ was adjusted to 5.3 with $\mathrm{NaOH}$ or $\mathrm{HCl}$; they were sterilized by autoclaving at $120^{\circ} \mathrm{C}$ for 20 minutes. The diesel oil $(5 \% \mathrm{v} / \mathrm{v})$ was used as substrate and was sterilized by flowing steam. The inoculum was incubated at $28^{\circ} \mathrm{C}$ and $150 \mathrm{rpm}$ for $48 \mathrm{~h}$. The final concentration of inoculum was around $10^{6}$ cells $/ \mathrm{mL}$ that were determined by counting in a Neubauer chamber. The components of the production media were weighed with the specifications as shown in Table 1. The diesel oil was used as substrate at 1, 3 or $5 \%(\mathrm{v} / \mathrm{v})$, sterilized by flowing steam and distributed as specified by the full $2^{4}$ factorial design (Table 1). Then, the inoculum $(5 \% \mathrm{v} / \mathrm{v})$ was transferred directly to $500 \mathrm{~mL}$ Erlenmeyer flasks, with a working volume of $300 \mathrm{~mL}$ which were kept under agitation $(150 \mathrm{rpm})$ for 168 hours at $28^{\circ} \mathrm{C}$. The statistical analysis of the results was carried out with the program Statistic version 8.0 (Statsoft - USA).

Table 1: Levels and values of independent variables of the full $2^{4}$ factorial design

\begin{tabular}{|l|c|c|c|}
\hline \multicolumn{2}{|l|}{$\begin{array}{l}\text { Independent } \\
\text { variables }\end{array}$} & \multicolumn{3}{|c|}{ Levels } \\
\cline { 2 - 4 } Diesel oil (\%v/v) & 1.0 & 3.0 & +1 \\
(NH2)2CO (\%p/v) & 0.10 & 0.25 & 0.40 \\
(NH4)2SO4 (\%p/v) & 0.10 & 0.60 & 1.10 \\
KH2PO4 (\%p/v) & 0.68 & 1.36 & 2.04 \\
\hline
\end{tabular}

\section{Analytical Determinations}

The analysis of the emulsification activity was performed according to the method described by Cirigliano and Carman (1984). Samples collected during the microorganism growth were filtered through Millipore ${ }^{\circledR}$ membranes (pore diameter of $0.22 \mu \mathrm{m})$. Cell-free aliquots $(2 \mathrm{~mL})$ were transferred to test tubes and diluted with $2 \mathrm{~mL}$ of $0.1 \mathrm{M}$ sodium acetate buffer ( $\mathrm{pH} 3.0)$. Then, $1 \mathrm{~mL}$ of corn oil was added; the mixture was vortexed for 2 minutes at $25^{\circ} \mathrm{C}$ in shaker tubes. After $10 \mathrm{~min}$ (at rest), the absorbance was measured. The culture medium was used as blank. One unit of emulsification activity (UEA) was defined as the amount of emulsifier required to produce an emulsion with absorbance equal to one at $540 \mathrm{~nm}$. 
The surface tension was determined by the ring method of du Noüy (ASTM D971, 1999), while the salinity and the density were determined by refractometry and the $\mathrm{pH}$ by potentiometry.

\section{RESULTS AND DISCUSSIONS}

The yeast $Y$. lipolytica was able to use diesel oil as substrate and to grow in natural sea water, supplemented with urea, ammonium sulfate and monobasic potassium phosphate, producing emulsification activities for corn oil after 168 hours. The main effects and interactions of independent variables on the response variable emulsification activity in the factorial design are illustrated in the Pareto Diagram (Figure 1). The decoded factorial design matrix and the results of each experimental condition of the $2^{4}$ factorial design are shown in Table 2.

\section{Effects of Nutrient Concentrations on Emulsification Activity and Surface Tension}

In the Pareto Diagram, shown in Figure 1, monobasic potassium phosphate did not present statistically significant effects on the emulsification activity. The interaction of this phosphate with diesel and with urea, showed highly significant effects from the statistical point of view, favoring an increase in emulsification activity. A curvature test was performed and revealed a lack of adjustment in the linear approximation. Figure 1 shows that the curvature crosses the confidence level of $95 \%$, indicating the proximity to the optimum point and the requirement for a second-order design and a quadratic model that incorporates the effect of the curvature. The Pareto Diagram of the dependent variable surface tension is not shown because the effects of the independent variables and their interactions were not statistically significant.

\section{Culture Medium Investigation for Bioemulsifier/ Biosurfactant Production}

In each of the twenty runs performed (Table 2), after $168 \mathrm{~h}$ the cell-free broth showed high emulsification activities, ranging between 5.45 and 6.00 UEA, compared to the values obtained by Albuquerque et al. (2006), who determined a maximum emulsification activity of 4.5415 UEA. Correlation was identified between high levels of emulsification activity and low surface tension. Despite the $\mathrm{pH}$ values between 4.92 and 6.00 (Table 2) and the literature information about yeasts preference for acid $\mathrm{pH}$, this parameter needs to be investigated for the production of biosurfactant by Y. lipolytica, since sea water had $\mathrm{pH} 8.22$. The salinity of the cellfree broth was between 42 and $65 \%$ (twice the amount of the sea water salinity). Few microorganisms are tolerant to seawater salinity. The genus Yarrowia is reported in the literature as presenting a high halophilic capacity (Ochoa and Vazquez-Juaréz, 2004).

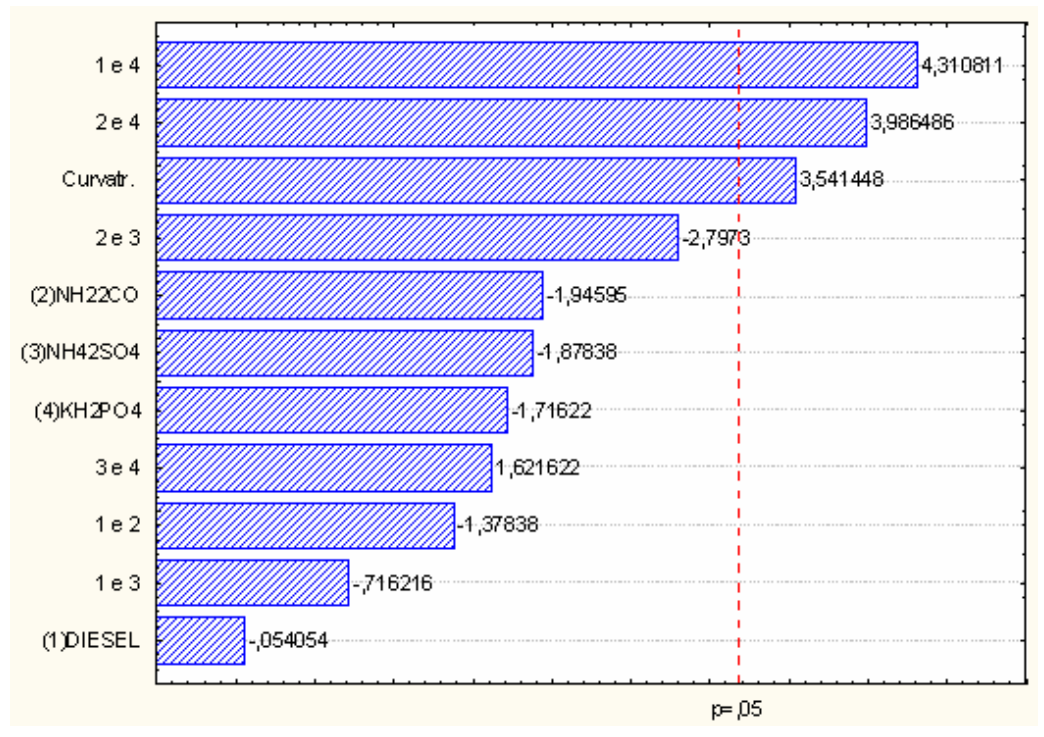

Figure 1: Pareto Diagram for $2^{4}$ factorial design; response variable: emulsification activity. The point, in which the estimated effects were statistically significant $(p=0.05)$, is indicated by a vertical dashed line. 
Table 2: Matrix for $2^{4}$ factorial design and decoded results of emulsifying activity (EA) for corn oil-inwater emulsion, surface tension (ST), pH and salinity of the cell-free cultures after 168 hours of cultivation in the presence of diesel oil as substrate.

\begin{tabular}{|c|c|c|c|c|c|c|c|c|}
\hline Run & $\begin{array}{c}\text { Diesel oil } \\
(\mathbf{\%} / \mathbf{v})\end{array}$ & $\begin{array}{c}\mathbf{( N H}_{\mathbf{2}} \mathbf{2}_{\mathbf{2}} \mathbf{C O} \\
(\mathbf{\%} / \mathbf{p} / \mathbf{)}\end{array}$ & $\begin{array}{c}\mathbf{( N H}_{\mathbf{4}} \mathbf{S}_{\mathbf{S}} \mathbf{S O}_{\mathbf{4}} \\
\mathbf{( \% )} / \mathbf{v})\end{array}$ & $\begin{array}{c}\mathbf{K H}_{\mathbf{2}} \mathbf{P O} \mathbf{H}_{\mathbf{4}} \\
(\mathbf{\%} \mathbf{p} / \mathbf{v})\end{array}$ & $\begin{array}{c}\mathbf{E A} \\
*(\mathbf{U E A})\end{array}$ & $\begin{array}{c}\mathbf{S T} \\
(\mathbf{M n} / \mathbf{m})\end{array}$ & $\begin{array}{c}\text { Salinity } \\
\mathbf{( \% )}\end{array}$ \\
\hline 1 & 1.0 & 0.10 & 0.10 & 0.68 & 6.000 & 49.22 & 5.14 & 46 \\
2 & 5.0 & 0.10 & 0.10 & 0.68 & 5.996 & 47.33 & 5.19 & 45 \\
3 & 1.0 & 0.40 & 0.10 & 0.68 & 5.872 & 49.14 & 6.08 & 42 \\
4 & 5.0 & 0.40 & 0.10 & 0.68 & 5.784 & 43.48 & 5.65 & 50 \\
5 & 1.0 & 0.10 & 1.10 & 0.68 & 6.000 & 52.55 & 5.44 & 53 \\
6 & 5.0 & 0.10 & 1.10 & 0.68 & 5.836 & 49.15 & 5.11 & 56 \\
7 & 1.0 & 0.40 & 1.10 & 0.68 & 5.844 & 46.28 & 5.87 & 46 \\
8 & 5.0 & 0.40 & 1.10 & 0.68 & 5.454 & 52.43 & 5.68 & 57 \\
9 & 1.0 & 0.10 & 0.10 & 2.04 & 5.654 & 50.84 & 4.97 & 53 \\
10 & 5.0 & 0.10 & 0.10 & 2.04 & 5.692 & 53.61 & 4.92 & 53 \\
11 & 1.0 & 0.40 & 0.10 & 2.04 & 5.830 & 49.21 & 6.02 & 55 \\
12 & 5.0 & 0.40 & 0.10 & 2.04 & 5.982 & 50.13 & 5.93 & 53 \\
13 & 1.0 & 0.10 & 1.10 & 2.04 & 5.658 & 49.13 & 5.07 & 61 \\
14 & 5.0 & 0.10 & 1.10 & 2.04 & 5.984 & 48.16 & 5.07 & 65 \\
15 & 1.0 & 0.40 & 1.10 & 2.04 & 5.682 & 47.16 & 5.85 & 61 \\
16 & 5.0 & 0.40 & 1.10 & 2.04 & 5.796 & 51.94 & 5.72 & 60 \\
17 & 3.0 & 0.25 & 0.60 & 1.36 & 6.000 & 51.44 & 5.39 & 49 \\
18 & 3.0 & 0.25 & 0.60 & 1.36 & 6.000 & 46.68 & 5.35 & 45 \\
19 & 3.0 & 0.25 & 0.60 & 1.36 & 5.852 & 49.56 & 5.41 & 51 \\
20 & 3.0 & 0.25 & 0.60 & 1.36 & 6.000 & 48.91 & 5.69 & 48 \\
\hline
\end{tabular}

* Unit of Emulsification Activity (UEA)

The highest emulsification activity (6.00 UEA) was determined in run 1 and in run 5, in the presence of $0.10 \%$ and $1.10 \%$ ammonium sulfate, respectively. Both of these experiments used diesel oil at $1 \%$ as substrate in the presence of $0.10 \%$ urea and $0.68 \%$ monobasic potassium phosphate. The maximum value was also determined at the central point of the factorial design (runs 17, 18 and 20); these conditions used diesel oil at 3\% in the presence of $0.25 \%$ urea, $0.60 \%$ ammonium sulfate and $1.36 \%$ monobasic potassium phosphate. The emulsification activity was independent of ammonium sulfate concentration (Table 2).

The nitrogen source is very important in the physiology of microorganisms in order to produce protein during cell growth. This nitrogen source (ammonium sulfate) is ammoniacal, commonly metabolized by microorganisms. On the other hand, urea is a nitrogen source of lower cost, sold as fertilizer.

The interaction between urea and monobasic potassium phosphate favored the increase of the emulsification activity. The interaction between the nitrogen sources was not statistically significant under the experimental conditions. These results are shown in the Pareto Diagram (Figure 1).

However, runs 1 and 5 presented surface tensions equal to 49.22 and $52.55 \mathrm{mN} / \mathrm{m}$, respectively, and showed a $\mathrm{pH}$ close to the initial value of the medium (pH 5.3) and a salinity higher than $46 \%$.
Although runs 1 and 5 showed higher emulsification activity (6.00 UAE), using diesel oil at lower concentration $(1 \% \mathrm{v} / \mathrm{v})$, run 4 had a lower surface tension $(43.48 \mathrm{mN} / \mathrm{m})$ in the presence of diesel fuel at the higher concentration $(5 \% \mathrm{v} / \mathrm{v})$, urea at $0.40 \%$, ammonium sulfate at $0.10 \%$ and monobasic potassium phosphate at $0.68 \%$. The initial surface tension of run 4 , after autoclaving, was equal to $60.25 \mathrm{mN} / \mathrm{m}$, making the reduction to $43.48 \mathrm{mN} / \mathrm{m}$ significant. Considering the great influence exerted by salinity $(50 \%)$ and $\mathrm{pH}(5.65)$ on the surface tension of the medium, run 4 demonstrated that its cell-free broth is a promising emulsifier.

There are several biosurfactants that lower the surface tension and stabilize emulsions (Singer et al., 1985; Rapp et al., 1979). One example is the sophorolipids of Torulopsis bombicola that have shown the ability to reduce surface tension and also proved to be good emulsifiers (Cooper and Paddock, 1984). On the other hand, the extracellular bioemulsifier Liposan from C. lipolytica is not able to reduce the surface tension of water $(72.8 \mathrm{mN} / \mathrm{m})$, but it effectively emulsifies and stabilizes water-inoil emulsions (Cirigliano and Carman, 1985).

Candida tropicalis in the presence of distilled water as a solvent of a mineral medium and $\mathrm{n}$-hexadecane as sole carbon source produced an extracellular emulsifier under nitrogen limitation in fed-batch culture. This emulsifier showed high emulsification activities for various hydrocarbons 
where the maximum value was related to the aromatic compounds. In these experimental conditions, although the surface tensions ranged from 49 to $52 \mathrm{mN} / \mathrm{m}$, the culture medium was equal to $68 \mathrm{mN} / \mathrm{m}$. This implies that the material excreted by the cell was a better emulsifier than a biosurfactant (Singh and Desai, 1989, Singh et al., 1990).

Cladosporium resinae was isolated from an aircraft tank. This microorganism grew in a mineral medium in the presence of distilled water and jet fuel as a sole carbon source. It produced an extracellular biosurfactant called Cladosan after twenty five days that reduced the surface tension of the aqueous phase from $72 \mathrm{mN} / \mathrm{m}$ to $50 \mathrm{mN} / \mathrm{m}$ and, after being partially purified, reduced the tension to $40 \mathrm{mN} / \mathrm{m}$ (Muriel et al., 1996).

Plaza et al. (2006) investigated the biosurfacatant/ bioemulsifier productions to sixteen species of bacteria, isolated from contaminated soil with petroleum hydrocarbons. The experiments were carried out in liquid cultures containing crude oil under thermophilic conditions. The results showed that although the reduction of surface tension was a good measure of biosurfactant production, it was not correlated with the emulsification activity.

In the experiments carried out with $Y$. lipolytica, high values of emulsification activities were not correlated with low surface tension. These results agree with those obtained by Singh et al. (1990); the authors produced a biopolymer with high emulsification activity, but no significant results for surface tension reduction during the Candida tropicalis growth. On the other hand, Albuquerque et al. (2006) obtained an emulsification activity for a water-in-n-hexadecane emulsion equal to $4.415 \mathrm{UAE}$ and a surface tension of $32.750 \mathrm{mN} / \mathrm{m}$ in optimal production medium, containing $0.544 \%$ of urea, $2.131 \%$ of ammonium sulfate, $2.628 \%$ of potassium phosphate, $5 \% \mathrm{v} / \mathrm{v}$ of corn oil, $50 \% \mathrm{v} / \mathrm{v}$ of distilled water and $50 \% \mathrm{v} / \mathrm{v}$ of sea water. According to the literature, this can be explained by the fact that the microorganism produces in some conditions only biossurfactants with emulsifier properties and, in others, biosurfactant with surface tension reducing activity (Cirigliano and Carman, 1984).

A consortium of bacteria isolated from a soil sample from Long Beach, contaminated with diesel oil, reduced the surface tension to $41.4 \mathrm{mN} / \mathrm{m}$ and increased the rate of emulsification to $64 \%$ after 14 hours of growth (Bento et al., 2005). Therefore, the surface tension reductions achieved by $Y$. lipolytica may be considered promising under the conditions of runs 2, 4, 7 and 15 of this work. The importance of monobasic phosphate potassium in bioemulsifier production in sea water is corroborated by studies that reported the production of emulsifiers by C. lipolytica in sea water diluted to $50 \%$, supplemented with sources of nitrogen and phosphorus, using corn oil (Albuquerque et al., 2006) and babassu oil (Harrop-Vance et al., 2003) as carbon sources.

Mariano et al. (2008) evaluated the production of a biosurfactant by Staphylococcus hominis, Kocuria palustris and Pseudonomas aeruginosa LBI using a mineral medium in the presence of diesel oil (weathered and commercial) at 1, 5, 10, 20 and 30\% $\mathrm{v} / \mathrm{v}$ as a low cost substrate. The production of biosurfactant was monitored by the surface tension. The experiments were carried out in Erlenmeyer flasks with a $50 \mathrm{~mL}$ working volume and $1 \mathrm{~mL}$ of a bacteria suspension (inoculum). The flasks were incubated at $27 \pm 2^{\circ} \mathrm{C}$ and $240 \mathrm{rpm}$ for 144 hours. The initial surface tensions of the culture media were in the range between 50 and $61 \mathrm{mN} / \mathrm{m}$, while the minimum surface tension determined was $45 \mathrm{mN} / \mathrm{m}$ after cultivation. The surface tension of the $P$. aeruginosa LBI grown in the presence of $10 \% \mathrm{v} / \mathrm{v}$ of weathered diesel decreased to approximately $45 \mathrm{mN} / \mathrm{m}$ (the maximum reduction determined). These authors adopted the criteria used by Habba $e t$ al. (2000): a good biosurfactant decreases the surface tension to a value equal to or less than $40 \mathrm{mN} / \mathrm{m}$. In other studies, $P$. aeruginosa LBI was able to produce rhamnolipid biosurfactant in the presence of soapstock (Moraes et al., 2002), diesel oil (Mariano et al., 2008) and n-hexadecane, glycerol, babassu oil and paraffin oil (Santa-Anna et al., 2002).

According to the criteria used by Habba et al. (2000), mentioned previously in this work, the yeast $Y$. lipolytica was not a good microorganism producer of biosurfactants, but it was a good producer of emulsifiers in the presence of diesel oil and sea water, supplemented with sources of nitrogen and phosphorus in all experimental conditions (Table 2).

Pornsunthorntawee et al. (2009) produced a biosurfactant by $P$. aeruginosa SP4 in a mineral medium supplemented with palm oil at different rates. The inoculum was grown in Erlenmeyer flask at $37^{\circ} \mathrm{C}$ and $200 \mathrm{rpm}$ for $22 \mathrm{~h}$. The experiments were carried out in a bioreactor with a capacity of $3000 \mathrm{~mL}$ and working volume of $1500 \mathrm{~mL}$ at $37 \pm 1^{\circ} \mathrm{C}$. The authors determined a surface tension reduction of $59 \%$ when palm oil was added at $2 \mathrm{~kg} / \mathrm{m}^{3}$.day with a cycle time of 2 days/cycle.

Rufino et al. (2011) produced a biosurfactant with antimicrobial properties from Candida lipolytica UCP 0988 in the presence of $0.1 \%$ $\mathrm{NH}_{4} \mathrm{NO}_{3}, \quad 0.02 \% \quad \mathrm{KH}_{2} \mathrm{PO}_{4}, \quad 0.02 \% \quad \mathrm{MgSO}_{4} \cdot 7 \mathrm{H}_{2} \mathrm{O}$, supplemented with soybean oil refinery residue and glutamic acid in 72 hours fermentation at $28^{\circ} \mathrm{C}$ in an 
orbital shaker at $150 \mathrm{rpm}$. The biosurfactant produced was able to reduce the surface tension from $50 \mathrm{mN} / \mathrm{m}$ to $25 \mathrm{mN} / \mathrm{m}$.

According to Sarubbo et al. (2007), Candida lipolytica synthesized a surfactant in a cultivation medium supplemented with canola oil and glucose as carbon sources after $48 \mathrm{~h}$ of fermentation. The cellfree broth was particularly influenced by the addition of salt, the $\mathrm{pH}$ and temperature depending on the emulsified substrate (hexadecane or a vegetable oil).

The emulsifier from Y. lipolytica, named Yansan, was different from previous emulsifiers. It presented high emulsification activity and stability in the $\mathrm{pH}$ range of $3.0-9.0$ and was capable of stabilizing oilin-water emulsions with several aliphatic and aromatic hydrocarbons (Amaral et al., 2006).

In the literature, bioemulsifier/biosurfactant production was not found associated with the utilization of diesel oil by $Y$. lipolytica in natural sea water, supplemented by sources of nitrogen and phosphorus.

In this study, the application of Y. lipolytica in the bioremediation of oil in seawater was investigated for the first time. The physiology of this yeast was investigated under saline conditions of sea water in the presence of diesel oil. In a second step, experiments under natural conditions are fundamental for investigation of the nutritional interactions of the microbial consortium between $Y$. lipolytica and the indigenous microorganisms of seawater.

Because $Y$. lipolytica is strictly aerobic, the investigation of oxygen transfer in the medium is very important to increase the metabolite production. Thus, an increase of stirring in the bioreactor should promote, in a second step, greater aeration and enhance the production of metabolites.

\section{CONCLUSIONS}

The production of emulsifiers by $Y$. lipolytica in saline conditions in the presence of diesel oil enables the application of this yeast in sea bioremediation of petroleum and oil spills, due to its ability to produce a bioemulsifier in the presence of sea water.

\section{ACKNOWLEDGMENTS}

This work was financially supported by the Coordenação de Aperfeiçoamento de Pessoal de Nível Superior (CAPES).

\section{REFERENCES}

Albuquerque, C. D. C., Fileti, A. M. F. and CamposTakaki, G. M., Optimizing the medium components in bioemulsifiers production by Candida lipolytica with response surface method. Canadian Journal of Microbiology, 52, n. 6, p. 575-583 (2006).

Amaral, P. F. F., Silva, J. M., Lehocky, M., BarrosTimmons, A. M. V., Coelho, M. A. Z., Marrucho, I. M. and Coutinho, J. A. P., Production and Characterization of a Bioemulsiftier from Yarrowia lipolytica. Process Biochemistry, 41, p. 1894-1898 (2006).

ASTM D971, 99th Standard test method for interfacial tension of oil against water by the ring. In: Method American Society for Testing Materials (1999).

Atlas, R. M., Pathways of microbial degradation of petroleum hydrocarbon: an environmental perspective. Microbiological Reviews, 45, p. 180209 (1984).

Bento, F. M., Camargo, F. A. O., Okeke, B. C. and Frankenberger-Jr, W. T., Diversity of biosurfactant producing microorganisms isolated from soils contaminated with diesel oil. Microbiological Research, 160, n. 3, p. 249-255 (2005).

Challain, F., Chaineau, C.H., Point, V., Saliot, A. and Oudot, J., Factors inhibiting bioremediation of soil contamination with weathered oils and drill cuttings. Environmental Pollution, 144, n. 1, p. 255-265 (2006).

Cirigliano, M. C. and Carman, G. M., Isolation of a bioemulsifier from Candida lipolytica. Applied and Environmental Microbiology, 48, p. 747-750 (1984).

Cirigliano, M. C. and Carman, G. M., Purification and characterization of liposan, a bioemulsifier from Candida lipolytica. Applied and Environmental Microbiology, 50, p. 846-850 (1985).

Cooper, D. G. and Padock, D. A., Production of a biosurfactant from Torulopsis bombicola. Applied and Environmental Microbiology, p. 173-176 (1984).

Desai, J. D. and Banat, I. M., Microbial production of surfactants and their commercial potential. Microbiology and Molecular Biology Reviews, 61, n. 1, p. 47-64 (1997).

Habba, E., Espuny, M. J., Busquets, M. and Manresa, A., Screening and production of rhamnolipids by Pseudomonas aeruginosa 47T2 
NCIB 40044 from waste frying oils. Journal of Applied Microbiology, 88, p. 379 (2000).

Herman D. C., Zhang Y., Miller R. M., Rhamnolipid (biosurfactant) effects on cell aggregation and biodegradation of residual hexadecane under saturated flow conditions. Applied and Environmental Microbiology, 63, p. 3622-3627 (1997).

Mariano, A. P., Bonotto, D. M., Angelis, D. F., Pirôllo, M. P. S. and Contiero, J., Use of weathered diesel oil as a low-cost raw material for biosurfactant production. Brazilian Journal of Chemical Engineering, 25, n. 2, p. 269-274 (2008).

Moraes, I. O., Benincasa, M. and Monte Alegre, R., Production and characterization of rhamnolipids produced by a newly isolated strain of Pseudomonas aeruginosa. Brazilian Journal of Food Technology, 5, p. 145-49 (2002).

Muriel, M. M., Bruque, J. M., Olías, J. M. and Jiménez-Sánchez, A., Production of biosurfactant by Cladosporium resinae. Biotechnology Letters, 18, n. 3, p. 235-240 (1996).

Ochoa, J. L. and Vázquez-Juárez, R., Las levaduras marinas como herramientas científica y biotecnológica - Marine yeasts as scientific and biotechnology tools. Universidad y Ciencia, n. 1, p. 39-50 (2004).

Plaza, G. A., Zjawiony, I. and Banat, I. M., Use of different methods for detection of thermophilic biosurfactant producing bacteria from hydrocarboncontaminated and bioremediated soils. Journal of Petroleum Science and Engineering, 50, p. 71-77 (2006).

Pornsunthorntawee, O., Maksung, S., Huayyai, O., Rujiravanit, R. and Chavadej, S., Biosurfactant production by Pseudomonas aeruginosa SP4 using sequencing batch reactors: Effects of oil loading rate and cycle time. Bioresource Technology, 100, p. 812-818 (2009).

Rapp, P., Bock, H., Wray, V. and Wagner, F.,
Formation, isolation and characterization of trehalose dimycolates from Rhodococcus erythropolis grown on n-alkanes. Journal of General Microbiology, 115, p. 491-503 (1979).

Rufino, R. D., Luna, J. M., Sarubbo L. A., Rodrigues, L. R. M., Teixeira, J. A. C., CamposTakaki, G. M., Antimicrobial and anti-adhesive potential of a biosurfactant Rufisan produced by Candida lipolytica UCP 0988. Colloids and Surfaces B: Biointerfaces, 84, p. 1-5 (2011).

Santa-Anna, L. M., Sebastian, G. V., Menezes, E. P., Alves, T. L .M., Santos, A. S., Pereira Jr., N. and Freire, D. M. G., Production of biosurfactants from Pseudomonas aeruginosa PA1 isolated in oil environments. Brazilian Journal of Chemical Engineering, 19, n. 02, p. 159-166 (2002).

Sarubbo, L. A., Farias, C. B. B., Campos-Takki, G. M., Co-utilization of canola oil and glucose on the production of a biosurfactant by Candida lipolytica. Current Microbiology, 54, n. 1, p. 6873 (2007).

Singer, T. P., Salach, J. I. and Crabtree, D., Reversible inhibition and mechanism-based irreversible inactivation of monoamine oxidases by 1-methyl-4-phenyl-1,2,3,6-tetrahydropyridine (MPTP). Biochemical and Biophysical Research Communications, 127, p. 707-712 (1985).

Singh, M. and Desai, J. D., Hydrocarbon emulsification by Candida tropicalis and Debaryomyces polymorphus. Indian Journal of Experimental Biology, 27, p. 224-226 (1989).

Singh, M., Saini, V. S., Adhikari, D. K., Desai, J. D. and Sista, V. R., Production of bioemulsifier by a SCP producing strain of Candida tropicalis during hydrocarbon fermentation. Biotechnology Letters, 12, n. 10, p. 743-746 (1990).

Vance-Harrop, M. H., Buarque-Gusmão, N. and Campos-Takaki, G. M., New bioemulsifiers produced by Candida lipolytica using D-glucose and babassu oil as carbon sources. Brazilian Journal of Microbiology, 34, p. 120-123 (2003). 